\title{
Redução da Proteína Bruta da Ração para Suínos Machos Castrados dos 15 aos 30 kg Mantidos em Termoneutralidade ${ }^{1}$
}

\author{
Rony Antonio Ferreira ${ }^{2}$, Rita Flávia Miranda de Oliveira ${ }^{3}$, Juarez Lopes Donzele ${ }^{3}$, \\ Darci Clementino Lopes ${ }^{3}$, Uislei Antonio Dias Orlando ${ }^{4}$, Wilkson de Oliveira Resende ${ }^{5}$, \\ Roberta Gomes Marçal Vieira Vaz ${ }^{6}$
}

\begin{abstract}
RESUMO - Um experimento foi conduzido para avaliar a influência da redução da proteína bruta (PB) e suplementação de aminoácidos sintéticos sobre o desempenho de suínos machos castrados mantidos em ambiente termoneutro $\left(22^{\circ} \mathrm{C}\right)$. Foram utilizados 60 leitões mestiços (Landrace x Large White) com peso médio inicial de 15,0 kg e idade média de 53,1 dias, em delineamento inteiramente ao acaso, com cinco tratamentos $(18,17,16,15$ e 14\% PB), seis repetições e dois animais por unidade experimental. As rações experimentais foram fornecidas à vontade até o final do experimento, quando os animais atingiram o peso médio de $30,2 \mathrm{~kg}$. A temperatura média no interior da sala foi mantida em $22^{\circ} \mathrm{C}$, com umidade relativa de $82,3 \%$. O Índice de Temperatura de Globo e Umidade calculado no período foi de 69,6 . Não se observou efeito da redução do nível de proteína bruta da ração sobre as variáveis de desempenho (consumo de ração, ganho de peso e conversão alimentar). As taxas de deposição de proteína e gordura também não foram influenciadas pela redução da PB na ração. Os tratamentos influenciaram os pesos absoluto e relativo do estômago e o peso absoluto do intestino, sendo os maiores valores observados em animais que receberam a ração com maior nível de proteína bruta. Concluiu-se que o nível de PB da ração pode ser reduzido de 18 para 14\%, sem prejudicar o desempenho de suínos machos dos 15 aos $30 \mathrm{~kg}$ mantidos em ambiente termoneutro, desde que devidamente suplementadas com aminoácidos essenciais limitantes.
\end{abstract}

Palavras-chave: aminoácidos, nutrição, suínos, termoneutralidade

\section{Reduction of Crude Protein Level of Ration to Castrated Swine from 15 to $30 \mathrm{~kg}$ Maintained in a Termoneutral Environment $\left(22^{\circ} \mathrm{C}\right)$}

\begin{abstract}
One experiment was conducted to evaluate the influence of reduction of the crude protein $(\mathrm{CP})$ level of ration with amino acid supplementation on performance of castrated males swines maintained in a termoneutral environment $\left(22^{\circ} \mathrm{C}\right)$. A total of sixty crossbred swines (Landrace x Large White), with average initial weight of $15.0 \mathrm{~kg}$ and 53.1 days old, was allotted to a completely randomized design with five treatments $(18,17,16,15$ and $14 \% \mathrm{CP})$, six replications and two animals per experimental unit. The experimental diets were fed ad libitum until the end of the experiment, when the animals reached the average weight of $30.2 \mathrm{~kg}$. The average temperature in the room was maintained in $22^{\circ} \mathrm{C}$ with relative humidity of $82.3 \%$. The Black Globe-Humidity Index (BGHI) was 69.6. No effect of decreasing dietary $\mathrm{CP}$ level on the evaluated performance parameters (feed intake, weight gain and feed:gain ratio) was observed. The deposition rates of protein and fat were not affected by the reduction of $\mathrm{CP}$ level and amino acid supplementation. The treatments affected the absolute and relative weight of stomach and absolute weight of intestine, and the highest weights were observed in the animals fed diet with the highest CP level. It was concluded that the dietary crude protein level can be reduced from 18 to $14 \%$ to castrated piglets from 15 to $30 \mathrm{~kg}$ maintained in a termoneutral environment with no effect on performance, since diets are supplemented with essential amino acids.
\end{abstract}

Key Words: amino acids, nutrition, swine, termoneutral environment

\section{Introdução}

A produção de suínos se mantém, atualmente, alicerçada em dois pilares, quais seriam: melhorar a produtividade e evitar a contaminação do meio ambiente com os dejetos. Uma maneira de reduzir a excreção de nitrogênio é diminuir a concentração de proteína da ração e suplementar aminoácidos, para atender as demandas para síntese protéica, assegurando-se maior eficiência na utilização dos nutrientes e produtividade dos suínos. Entretanto, de acordo com Figueroa et al. (2000), a redução drástica do nível de proteína bruta na ração para suínos em crescimento pode reduzir o desempenho, devido ao

\footnotetext{
1 Parte da tese de Doutorado apresentada à UFV. Pesquisa parcialmente financiada pela FAPEMIG.

2 Professor Associado LZNA - UENF, Campos dos Goytacazes, RJ. CEP: 28013-602. E.mail: rony@uenf.br

3 Professor da UFV. E.mail: flavia@ufv.br; donzele@ufv.br; dclopes@ufv.br

4 Doutor em Zootecnia/UFV. E.mail: und@perdigao.com.br

5 Aluno de Mestrado/UFV.

6 Aluno de Doutorado/UFV. E.mail: robertavaz@lycos.com
} 
menor aporte de aminoácidos não-essenciais.

As rações práticas utilizadas pelos criadores de suínos no Brasil, à base de milho e farelo de soja, formuladas para atender à exigência dos animais em lisina, contêm quantidades excessivas de outros aminoácidos, resultando em rações com nível protéico acima das suas necessidades. Esse excesso é catabolizado, acarretando sobrecarga principalmente ao fígado e aos rins no processo de eliminação de nitrogênio. A conseqüência, de acordo com Miyada (1999), é o aumento na produção de calor metabólico, fazendo que o animal reduza a ingestão de alimento e de outros nutrientes indispensáveis para produção. As rações desbalanceadas ou com excesso de aminoácidos representam uma fonte onerosa de energia metabolizável e um problema ambiental, devido à excessiva excreção de nitrogênio nos dejetos dos suínos (Parsons \& Baker, 1994).

Maiores volumes de urina e dejetos foram observados por Pfeiffer et al. (1995) quando os suínos em fase de crescimento foram alimentados com rações contendo níveis elevados de proteína. De acordo com o Nutrient... (1998), o suíno tolera altos níveis de proteína na ração, no entanto, além do acréscimo no custo de produção, a elevada concentração dietética de proteína tem implicações negativas na produtividade e no meio ambiente.

A substituição da proteína dietética pela suplementação de aminoácidos pode reduzir o impacto ambiental, e as quantidades adicionais de cloro $(\mathrm{Cl})$ fornecidas pela lisina- $\mathrm{HCl}$ podem exercer efeito mínimo sobre o equilíbrio ácido-base e sobre o desempenho dos animais. Porém, segundo Patience (1990), quando, além de lisina, outros aminoácidos como treonina e triptofano são adicionados em grandes quantidades às rações, eles podem propiciar dietas acidogênicas, com efeitos negativos sobre o desempenho. Nesse caso, a correção do equilíbrio ácido-base torna-se imprescindível para garantir a produtividade dos animais.

Outro aspecto importante a ser considerado em um sistema de produção é a temperatura ambiente, que é um dos principais elementos climáticos não só devido ao efeito que esta tem sobre a intensidade das trocas térmicas, como indiretamente pela influência que exerce sobre os demais componentes do microclima. Segundo Perdomo (1998), a adequação do meio deve ter caráter permanente, independentemente da maior ou menor habilidade genética do suíno. A estabilização e a melhoria do conforto térmico são fundamentais para minimizar a relação de dependência do suíno com as edificações e o clima, visando à otimização do desempenho.

Segundo Le Dividich (1991), a faixa de temperatura entre 20 e $25^{\circ} \mathrm{C}$ seria considerada ideal para suínos em crescimento, para melhor desempenho produtivo e qualidade de carcaça.

Este estudo foi realizado com o objetivo de avaliar os efeitos da redução na proteína bruta da ração com suplementação de aminoácidos sobre o desempenho de suínos machos castrados dos 15 aos $30 \mathrm{~kg}$, mantidos em ambiente de termoneutralidade.

\section{Material e Métodos}

O experimento foi conduzido no Setor de Suinocultura do Departamento de Zootecnia do Centro de Ciências Agrárias da Universidade Federal de Viçosa, em Viçosa, MG.

Foram utilizados 60 leitões mestiços (Landrace $\mathrm{x}$ Large White) machos castrados, em fase inicial de crescimento, com idade de 53,1 $\pm 3,4$ dias, peso inicial de $15,0 \pm 0,39$ e final de $30,2 \pm 0,84 \mathrm{~kg}$, distribuídos em delineamento experimental inteiramente casualizado, com cinco tratamentos $(18,17,16,15$ e $14 \%$ de proteína bruta na ração), seis repetições e dois animais por unidade experimental, mantidos em ambiente de termoneutralidade $\left(22^{\circ} \mathrm{C}\right)$.

Os animais foram alojados em gaiolas metálicas suspensas, com piso ripado e laterais teladas, providas de comedouro semi-automático e bebedouro tipo chupeta, mantidas em sala de alvenaria com piso de creche, janelões de vidro tipo basculante, teto com forro de madeira e telhas de barro tipo francesas.

A temperatura interna da sala foi mantida por meio de um conjunto de seis campânulas elétricas, distribuídas em dois corredores, a aproximadamente $40 \mathrm{~cm}$ do piso, ligadas a um termostato regulado para a temperatura de $21,5^{\circ} \mathrm{C}$, e por dois aparelhos de arcondicionado de $30.000 \mathrm{BTU}$, ligados a um termostato regulado para a temperatura de $22,5^{\circ} \mathrm{C}$.

As condições internas da sala foram monitoradas diariamente, sendo as leituras dos equipamentos realizadas três vezes ao dia. Foram utilizados termômetros de bulbo seco e bulbo úmido, termômetros de máxima e de mínima e termômetro de globo negro, mantidos em uma gaiola vazia no centro da sala, à meia altura do corpo do animal. As leituras dos termômetros foram convertidas em 
um único valor (Índice de Temperatura de Globo e Umidade - ITGU), para caracterizar o ambiente térmico ao qual os animais foram submetidos.

A temperatura interna da sala manteve-se durante o período experimental em $22,0 \pm 0,70^{\circ} \mathrm{C}$, a umidade relativa em $82,3 \pm 3,52$ e a temperatura de globo negro em $22,3 \pm 0,47^{\circ} \mathrm{C}$. O Índice de Temperatura de Globo e Umidade (ITGU) calculado no período foi de $69,6 \pm 0,53$. A temperatura de $22,0^{\circ} \mathrm{C}$, ocorrida neste trabalho, pode ser caracterizada como uma temperatura de termoneutralidade, por estar na faixa considerada ideal $\left(18-22^{\circ} \mathrm{C}\right)$ para esta categoria animal, conforme estabelecido por Esmay (1982) e por Nääs et al. (1995 e 1998), citados por Silva (1999).

As rações experimentais (Tabela 1) foram isolisínicas digestíveis, e os demais aminoácidos foram suplementados para atender as relações estabelecidas por Chung \& Baker (1992). Os níveis de proteína bruta na ração foram obtidos pela variação proporcional da quantidade de milho e farelo de soja. As rações foram devidamente suplementadas com minerais e vitaminas e o nível de energia foi corrigido pela variação na quantidade de amido, tornando-as isoenergéticas. Na determinação dos aminoácidos digestíveis dos ingredientes utilizados foram aplicados os coeficientes de digestibilidade propostos pelas tabelas Rhodimet... (1993). As rações experimentais e a água foram fornecidas à vontade e as sobras de ração foram recolhidas e pesadas semanalmente. O controle do ganho de peso, determinação do consumo de ração e cálculo da conversão alimentar também foram efetuados a cada semana.

Um grupo adicional de cinco leitões com peso de

Tabela 1 - Composição das rações experimentais

Table 1 - Composition of the experimental rations

\begin{tabular}{|c|c|c|c|c|c|}
\hline \multirow[t]{2}{*}{$\begin{array}{l}\text { Ingredientes } \\
\text { Ingredients }\end{array}$} & \multicolumn{5}{|c|}{$\begin{array}{l}\text { Níveis de proteína bruta }(\%) \\
\text { Crude protein levels }\end{array}$} \\
\hline & 18 & 17 & 16 & 15 & 14 \\
\hline Milho $($ Corn $)(7,75 \% \mathrm{~PB})^{1}$ & 67,265 & 63,525 & 59,790 & 56,056 & 52,314 \\
\hline Farelo soja (Soybean meal) $(45,5 \% \mathrm{~PB})^{1}$ & 28,192 & 26,625 & 25,059 & 23,494 & 21,926 \\
\hline Amido (Corn starch) & 0,490 & 5,300 & 10,130 & 14,930 & 19,780 \\
\hline Fosfato bicálcico (Dicalcium phosphate) & 1,408 & 1,495 & 1,580 & 1,670 & 1,755 \\
\hline Calcário (Limestone) & 0,677 & 0,639 & 0,605 & 0,565 & 0,530 \\
\hline Mistura mineral (Mineral mix) ${ }^{2}$ & 0,100 & 0,100 & 0,100 & 0,100 & 0,100 \\
\hline Mistura vitamínica (Vitamin mix) ${ }^{3}$ & 0,100 & 0,100 & 0,100 & 0,100 & 0,100 \\
\hline Sal comum (Salt) 0,250 & 0,255 & 0,260 & 0,267 & 0,272 & \\
\hline BHT (Antioxidant) & 0,010 & 0,010 & 0,010 & 0,010 & 0,010 \\
\hline Óleo de soja (Soybean oil) & 1,000 & 1,000 & 1,000 & 1,000 & 1,000 \\
\hline DL-Metionina (DL-Methionine) & 0,014 & 0,043 & 0,072 & 0,100 & 0,129 \\
\hline $\mathrm{L}-\mathrm{Lisina} \mathrm{HCl}$ (L-Lysine $\mathrm{HCl})$ & 0,000 & 0,060 & 0,119 & 0,180 & 0,240 \\
\hline L-Treonina (L-Threonine) & 0,000 & 0,000 & 0,010 & 0,046 & 0,081 \\
\hline Areia lavada (Washed sand) & 0,494 & 0,848 & 1,165 & 1,482 & 1,763 \\
\hline Total & 100,000 & 100,000 & 100,000 & 100,000 & 100,000 \\
\hline \multicolumn{6}{|l|}{ Composição calculada (Calculated composition) ${ }^{4}$} \\
\hline Proteína bruta (Crude protein) (\%) & 18,00 & 17,00 & 16,00 & 15,00 & 14,00 \\
\hline $\mathrm{ED}$ (Digestible energy) (kcal/kg) & 3.400 & 3.400 & 3.400 & 3.400 & 3.400 \\
\hline Lisina total (Total lysine) $(\%)$ & 0,964 & 0,957 & 0,950 & 0,944 & 0,938 \\
\hline Lisina dig (Digestible lysine) (\%) & 0,846 & 0,846 & 0,846 & 0,846 & 0,846 \\
\hline Met + Cis dig $(\%)$ (Digestible methionine + cystine $)$ & 0,524 & 0,524 & 0,524 & 0,524 & 0,524 \\
\hline Treonina dig (Digestible threonine) $(\%)$ & 0,626 & 0,592 & 0,567 & 0,567 & 0,567 \\
\hline Triptofano dig (\%) (Digestible tryptophan) & 0,217 & 0,205 & 0,193 & 0,181 & 0,169 \\
\hline Isoleucina dig (Digestible isoleucine) (\%) & 0,734 & 0,693 & 0,652 & 0,612 & 0,571 \\
\hline Cálcio (Calcium) $(\%)$ & 0,700 & 0,700 & 0,700 & 0,700 & 0,700 \\
\hline Fósforo total (Total phosphorus) (\%) & 0,550 & 0,550 & 0,550 & 0,550 & 0,550 \\
\hline
\end{tabular}

${ }_{1}^{1}$ Análises realizadas no Laboratório de Nutrição Animal do DZO/UFV (Analyses were performed at the Animal Nutrition Lab of UFV).

${ }^{2}$ Conteúdo/kg (Content/kg): $100 \mathrm{~g} \mathrm{Fe} ; 10 \mathrm{~g} \mathrm{Cu} ; 1 \mathrm{~g} \mathrm{Co} ; 40 \mathrm{~g} \mathrm{Mn} ; 100 \mathrm{~g} \mathrm{Zn;} 1,5 \mathrm{~g} \mathrm{I} ; 1.000 \mathrm{~g}$ excipiente (vehicle) q.s.p.

${ }^{3}$ Conteúdo/kg (Content/kg): vit A - 6.000.000 UI; $\mathrm{D}_{3}-1.500 .000$ UI; E - 15.000 UI; $\mathrm{B}_{1}$ - 1,35; $\mathrm{B}_{2}$ - 4 g; $\mathrm{B}_{6}$ - 2 g; ácido pantotênico (Pantotenic acid) - 9,35 g; vit $\mathrm{K}_{3}$ - 1,5 g; ácido nicotínico (Nicotinic acid) - 20,0 g; vit $\mathrm{B}_{12}$ - 20,0 g; ácido fólico (Folic acid) - 0,6 g; biotina (Biotin) - 0,08 g; selênio (Selenium) - 0,3 g; excipiente (vehicle) q.s.p. - $1.000 \mathrm{~g}$.

4 Composição calculada segundo Rostagno et al. (1992) (Composition calculated according to Rostagno et al., 1992). 
$14,4 \pm 1,43 \mathrm{~kg}$ foi abatido, seguindo-se o procedimento descrito para determinação da composição da carcaça dos animais no início do experimento e posterior determinação das taxas de deposição de proteína e gordura, conforme técnica descrita por Donzele et al. (1992).

Ao término do período experimental, os animais foram submetidos a jejum alimentar de 24 horas, sendo um animal de cada unidade experimental abatido por dessensibilização e sangramento. Após o abate, procedeu-se ao toalete e à evisceração, para retirada dos órgãos. O fígado, os rins, o intestino delgado e o estômago foram dependurados à sombra, para o escorrimento do sangue, por aproximadamente 20 minutos, sendo em seguida pesados.

As carcaças inteiras evisceradas e sem sangue, incluindo cabeça e pés, foram pesadas e trituradas em "cutter" comercial de 30 HP e 1.775 revoluções por minuto, por 15 minutos. Após homogeneização, retiraram-se amostras, que foram armazenadas em congelador a $-12^{\circ} \mathrm{C}$. Ao preparar as amostras para análises laboratoriais, em função da alta concentração de gordura do material, procedeu-se à pré-secagem em estufa, com ventilação forçada a $60^{\circ} \mathrm{C}$, por 72 horas. Em seguida, foi realizado o prédesengorduramento, pelo método a quente, em aparelho extrator do tipo "Soxhlet", por quatro horas, para posteriormente efetuar-se a moagem do material. As amostras pré-secas e pré-desengorduradas foram moídas e acondicionadas em vidros, para posteriores análises laboratoriais. Para correção dos valores das análises subseqüentes, foram consideradas a água e a gordura retiradas no preparo das amostras.

As análises de matéria seca, proteína e gordura das amostras foram realizadas de acordo com o método descrito por Silva (1990), no Laboratório de Nutrição Animal do Departamento de Zootecnia da UFV.

As análises estatísticas das variáveis de desempenho (ganho de peso, consumo de ração e conversão alimentar), de taxas de deposição de proteína e gordura nas carcaças e de pesos dos órgãos foram realizadas utilizando-se o procedimento GLM do SAS, versão 6.12 (1996), sendo a soma de quadrados dos tratamentos decomposta em contrastes ortogonais, seguindo-se o modelo estatístico a seguir:

$$
\mathrm{Y}_{\mathrm{ij}}=\mu+\mathrm{E}_{\mathrm{i}}+\varepsilon_{\mathrm{ij}}
$$

em que: $Y_{\mathrm{ij}}=$ ganho de peso, consumo de ração, conversão alimentar, taxas de deposição de proteína e gordura e pesos dos órgãos referentes ao nível de proteína i na repetição $\mathrm{j} ; \mu=$ média geral da caracte- rística; $\mathrm{E}_{\mathrm{i}}=$ efeito do nível de proteína bruta $\mathrm{i}$, sendo $\mathrm{i}=18,17,16$, 15 e $14 \%$ na ração; e $\varepsilon_{\mathrm{ij}}=$ erro aleatório associado a cada observação.

A avaliação da possibilidade de redução da proteína bruta da ração com suplementação de aminoácidos foi feita com base nos resultados de ganho de peso, consumo de ração, conversão alimentar, consumos de lisina e energia digestíveis, consumo de nitrogênio $(\mathrm{N})$, eficiência de utilização de nitrogênio para ganho e taxas de deposição de proteína e gordura na carcaça.

\section{Resultados e Discussão}

O valor de ITGU, que caracterizou o ambiente de termoneutro neste trabalho $(69,6)$, foi similar àquele de 70,7, obtido por Oliveira (1996) trabalhando com suínos machos castrados dos 15 aos $30 \mathrm{~kg}$, assim como o valor de 69,1 , obtido por Tavares et al. (2000), ambos mantidos em condições de termoneutralidade.

Os resultados de desempenho (ganho de peso, consumo de ração e conversão alimentar), consumos de lisina e energia digestíveis, consumo de nitrogênio, eficiência de utilização de nitrogênio para ganho, relação lisina:proteína bruta e taxas de deposição de proteína (TDP) e gordura (TDG) na carcaça dos suínos são apresentados na Tabela 2 .

O ganho de peso diário (GPD) não foi influenciado $(\mathrm{P}>0,10)$ pela redução do nível de proteína bruta $(\mathrm{PB})$ da ração. Esse resultado corrobora aqueles apresentados por Canh et al. (1998), que não verificaram influência da redução da PB sobre o ganho de peso de suínos na fase de crescimento. Da mesma forma, Figueroa et al. (2001), trabalhando com leitoas em crescimento, também observaram que a proteína bruta da ração pode ser reduzida de 16 para $12 \%$ sem influenciar o GPD dos animais, desde que mantida a relação ideal entre os aminoácidos das rações, o que pode ser obtido com a suplementação de aminoácidos.

Os animais que receberam a ração com menor nível de PB (14\%) apresentaram ganho de peso $1,8 \%$ superior àqueles que receberam a ração com $18 \%$ de $\mathrm{PB}$, evidenciando que a $\mathrm{PB}$ da ração pode ser reduzida sem efeitos negativos no ganho de peso dos animais. Esse resultado contrasta com os obtidos por Figueroa et al. (2000), quando observaram que a redução da $\mathrm{PB}$ da ração em níveis superiores a $4 \%$ (de 16 para $11 \%$ ) prejudicou o ganho de peso e a eficiência alimentar. 
Tabela 2 - Resultados de desempenho, consumos de lisina, energia digestível (ED) e nitrogênio (N), eficiência de utilização de nitrogênio para ganho (EUNG), relação lisina:proteína bruta (Lis:PB) e taxas de deposição de proteína e de gordura em suínos dos 15 aos $30 \mathrm{~kg}$ mantidos em ambiente termoneutro

Table 2 - Results of performance, intakes of digestible lysine, energy (DE) and nitrogen ( $N$ ), efficiency of $N$ utilization for gain (EUNG), lysine:protein ratio (Lys:CP) and deposition rates of protein and fat of swines from 15 to $30 \mathrm{~kg}$ maintained in a thermoneutral environment

\begin{tabular}{|c|c|c|c|c|c|c|}
\hline \multirow[t]{2}{*}{$\begin{array}{l}\text { Variáveis }^{1} \\
\text { Variables }\end{array}$} & \multicolumn{5}{|c|}{$\begin{array}{l}\text { Proteína bruta }(\%) \\
\text { Crude protein }\end{array}$} & \multirow[t]{2}{*}{$\mathrm{CV} \%$} \\
\hline & 18 & 17 & 16 & 15 & 14 & \\
\hline $\begin{array}{l}\text { Ganho de peso }(\mathrm{g} / \mathrm{d}) \\
\text { Weight gain }\end{array}$ & $641^{\mathrm{a}}$ & $671^{\mathrm{a}}$ & $628^{\mathrm{a}}$ & $641^{\mathrm{a}}$ & $653^{\mathrm{a}}$ & 11,9 \\
\hline $\begin{array}{l}\text { Consumo de ração }(\mathrm{g} / \mathrm{d}) \\
\text { Feed intake }\end{array}$ & $1167^{\mathrm{a}}$ & $1226^{\mathrm{a}}$ & $1161^{\mathrm{a}}$ & $1200^{\mathrm{a}}$ & $1200^{\mathrm{a}}$ & 9,2 \\
\hline $\begin{array}{l}\text { Conversão alimentar }(\mathrm{g} / \mathrm{g}) \\
\text { Feed / gain ratio }\end{array}$ & $1,83^{\mathrm{a}}$ & $1,83^{\mathrm{a}}$ & $1,84^{\mathrm{a}}$ & $1,87^{\mathrm{a}}$ & $1,85^{\mathrm{a}}$ & 6,6 \\
\hline $\begin{array}{l}\text { Consumo de lisina dig. } \\
\text { Digestible lysine intake }\end{array}$ & $9,89^{\mathrm{a}}$ & $10,38^{\mathrm{a}}$ & $9,83^{\mathrm{a}}$ & $10,17^{\mathrm{a}}$ & $10,16^{\mathrm{a}}$ & 9,2 \\
\hline $\begin{array}{l}\text { Consumo ED }(\mathrm{kcal} / \mathrm{d}) \\
\text { Energy intake }\end{array}$ & $3969^{a}$ & $4169^{\mathrm{a}}$ & $3949^{a}$ & $4080^{\mathrm{a}}$ & $4082^{\mathrm{a}}$ & 9,1 \\
\hline $\begin{array}{l}\text { Consumo de } \mathrm{N}(\mathrm{g} / \mathrm{d})^{1} \\
\text { Nitrogen intake }\end{array}$ & $33,6^{\mathrm{a}}$ & $33,3^{\mathrm{a}}$ & $29,7^{\mathrm{ab}}$ & $28,8^{\mathrm{ab}}$ & $26,9^{\mathrm{b}}$ & 9,1 \\
\hline $\begin{array}{l}\text { EUNG }(\mathrm{gGP} / \mathrm{gN})^{1} \\
\text { Relação Lis:PB }(\%) \\
\text { Lys:CP ratio }\end{array}$ & $\begin{array}{r}19,0^{\mathrm{c}} \\
5,35\end{array}$ & $\begin{array}{c}20,2^{\mathrm{bc}} \\
5,63\end{array}$ & $\begin{array}{c}21,2^{\mathrm{bc}} \\
5,94\end{array}$ & $\begin{array}{c}22,2^{\mathrm{ab}} \\
6,29\end{array}$ & $\begin{array}{c}24,2^{\mathrm{a}} \\
6,7\end{array}$ & $\begin{array}{l}6,8 \\
-\end{array}$ \\
\hline \multicolumn{7}{|c|}{$\begin{array}{l}\text { Taxas de deposição na carcaça } \\
\text { Deposition rate in the carcass }\end{array}$} \\
\hline $\begin{array}{l}\text { Proteína }(\mathrm{g} / \mathrm{d}) \\
\text { Protein }\end{array}$ & $79^{a}$ & $81^{\mathrm{a}}$ & $74^{\mathrm{a}}$ & $77^{a}$ & $81^{\mathrm{a}}$ & 10,8 \\
\hline $\begin{array}{l}\text { Gordura }(\mathrm{g} / \mathrm{d}) \\
\text { Fat }\end{array}$ & $84^{\mathrm{a}}$ & $92^{\mathrm{a}}$ & $92^{\mathrm{a}}$ & $88^{\mathrm{a}}$ & $89^{\mathrm{a}}$ & 15,8 \\
\hline
\end{tabular}

${ }_{1}^{1}(P<0,01)$ Médias seguidas de mesma letra na linha não diferem entre si, em contrastes múltiplos.

$1(P<0.01)$ Means followed by same letter in a line are not different by multiple contrasts.

O consumo de ração diário (CRD) também não foi influenciado $(\mathrm{P}>0,10)$ pela redução da proteína bruta da ração, todavia os animais que receberam a ração com o menor nível protéico (14\%) apresentaram, em valores absolutos, um CRD 2,8\% superior àqueles que receberam a ração com $18 \%$ de $\mathrm{PB}$.

Os resultados observados neste estudo são semelhantes àqueles apresentados por Canh et al. (1998), que não verificaram influência da redução de 16,5 para 12,5\% no nível de proteína bruta da ração, com suplementação de aminoácidos para suínos em crescimento. Resultados semelhantes foram apresentados por Figueroa et al. (2000) que, ao avaliarem a redução da proteína bruta e da suplementação de aminoácidos na ração de suínos dos 20 aos $50 \mathrm{~kg}$ de peso, não observaram efeitos sobre o consumo.

Por outro lado, Hansen et al. (1993), utilizando suínos dos 20 aos $50 \mathrm{~kg}$, observaram que rações com $12 \%$ de PB, mesmo suplementadas com aminoácidos, proporcionaram resultados de desempenho inferiores aos obtidos com rações com 16\% de PB. Esses autores concluíram que a redução do nível de $\mathrm{PB}$ deve ser realizada até dois pontos percentuais, para não comprometer o desempenho dos animais.

A conversão alimentar não foi influenciada $(\mathrm{P}>0,10)$ pelos tratamentos utilizados. Os resultados observados neste estudo são coerentes com os apresentados por Myer \& Bucklin (1995), que, estudando o efeito da suplementação dietética de lisina para suínos na fases de crescimento e terminação, sob condições de calor e conforto térmico, não observaram diferença na eficiência alimentar dos animais nos dois ambientes. No entanto, diferem daqueles apresentados por Miller et al. (1996), que verificaram pior conversão alimentar de suínos em crescimento (29 kg), mantidos em ambiente termoneutro, recebendo dietas com níveis variáveis de proteína (19,1 a $14,6 \%$ ) suplementadas com aminoácidos. Da mesma maneira, De La Llata et al. (2000), trabalhando com suínos em fase de crescimento, observaram pior desempenho dos animais (ganho de peso e CA), quando o nível de suplementação de lisina foi acima de $0,15 \%$ na ração. Tal fato ocorreu porque a ração 
foi suplementada somente com lisina, estando, provavelmente, deficiente em outros aminoácidos. Figueroa et al. (2001) também relataram que a redução do nível de proteína bruta de 16 para $12 \%$ prejudicou a conversão alimentar de leitoas com $23 \mathrm{~kg}$.

Uma vez que as rações eram isolisínicas e isoenergéticas, a ausência de efeito no consumo de ração implicou em respostas semelhantes $(\mathrm{P}>0,10)$ nos consumos de lisina (CL) e de energia digestível (CED), com a redução dos níveis dietéticos de proteína bruta.

Com a redução dos níveis de $\mathrm{PB}$ e a não variação no $\mathrm{CR}$ foi observada diminuição $(\mathrm{P}<0,01)$ gradativa na ingestão diária de nitrogênio $(\mathrm{N})$, a medida em que os níveis de $\mathrm{PB}$ da ração foram reduzidos. Os animais que receberam a ração com $14 \%$ de $\mathrm{PB}$ tiveram o consumo de $\mathrm{N}$ reduzido em 19,2 e 20,0\% em relação àqueles que receberam as rações com 17 e 18\% de $\mathrm{PB}$, respectivamente, não diferindo entre os demais tratamentos. A eficiência de utilização de nitrogênio para ganho (EUNG) aumentou gradativamente $(\mathrm{P}<0,01)$, sendo o maior valor observado com os animais que receberam a ração com 14\% de PB. Os resultados de EUNG obtidos neste estudo justificam a semelhança dos valores absolutos de deposição de proteína ocorridos nos animais que receberam as rações com 14 e 17\% de PB.

Os resultados obtidos no presente estudo estão coerentes com aqueles relatados por Lopez et al. (1994). Esses autores, que avaliaram os efeitos de rações formuladas com base na proteína ideal, verificaram que suínos em terminação alimentados com ração formulada com base na proteína ideal apresentaram menor consumo de $\mathrm{N}$ e exibiram a maior eficiência na utilização da proteína.

As taxas de deposição de proteína (TDP) e de gordura (TDG) na carcaça não foram influenciadas $(\mathrm{P}>0,10)$ pela redução da proteína das rações. A ausência de efeitos entre tratamentos permitiu deduzir que a ingestão diária de energia atendeu as demandas metabólicas para deposição de proteína e gordura dos animais. Este resultado seria indicativo de que, provavelmente, a retenção de nitrogênio não foi comprometida pela redução do nível de proteína bruta entre os tratamentos.

Os resultados obtidos neste estudo contrastam com aqueles obtidos por Tuitoek et al. (1997) e com os de Smith et al. (1997), que, avaliando a redução da $\mathrm{PB}$ em rações para suínos em crescimento, verificaram maior deposição gordura nos animais que receberam a ração com menor nível de $\mathrm{PB}$. Em revisão sobre a redução da proteína bruta da ração e suplementação de aminoácidos, Kidd (2001) relatou que essa prática não compromete o desempenho dos animais, exceto pela maior deposição de gordura em suínos e de gordura abdominal em frangos de corte alimentados com rações de baixa $\mathrm{PB}$.

Os dados de TDP obtidos neste trabalho estão de acordo com os verificados por Figueroa et al. (2000),

Tabela 3 - Resultados de pesos absolutos (g) e relativos (\% da carcaça) de fígado, rins, estômago e intestino de leitões de $30 \mathrm{~kg}$ mantidos em ambiente termoneutro

Table 3 - Results of absolute $(\mathrm{g})$ and relative (\% of carcass) weights of liver, kidneys, stomach and intestine of swines of $30 \mathrm{~kg}$ maintained in a thermoneutral environment

\begin{tabular}{|c|c|c|c|c|c|c|}
\hline \multirow[t]{2}{*}{$\begin{array}{l}\text { Variáveis }{ }^{1} \\
\text { Variables }\end{array}$} & \multicolumn{5}{|c|}{$\begin{array}{c}\text { Proteína bruta }(\%) \\
\text { Crude protein }\end{array}$} & \multirow[t]{2}{*}{$\mathrm{CV} \%$} \\
\hline & 18 & 17 & 16 & 15 & 14 & \\
\hline \multicolumn{7}{|c|}{$\begin{array}{l}\text { Peso absoluto (g) } \\
\text { Absolute weight }\end{array}$} \\
\hline Fígado (Liver) & $772^{\mathrm{a}}$ & $734^{\mathrm{a}}$ & $772^{\mathrm{a}}$ & $756^{\mathrm{a}}$ & $743^{\mathrm{a}}$ & 7,5 \\
\hline Rins (Kidneys) & $130^{\mathrm{a}}$ & $134^{\mathrm{a}}$ & $122^{\mathrm{a}}$ & $116^{\mathrm{a}}$ & $129^{\mathrm{a}}$ & 8,7 \\
\hline Estômago (Stomach) & $213^{\mathrm{a}}$ & $202^{b}$ & $190^{\mathrm{bc}}$ & $185^{\mathrm{bc}}$ & $206^{\mathrm{b}}$ & 8,5 \\
\hline Intestino $^{2}$ (Intestine) & $1.084^{\mathrm{a}}$ & $1.054^{\mathrm{a}}$ & $1.057^{\mathrm{a}}$ & $963^{b}$ & $1.001^{\mathrm{ab}}$ & 6,5 \\
\hline \multicolumn{7}{|c|}{$\begin{array}{c}\text { Peso relativo (\%) } \\
\text { Relative weight }\end{array}$} \\
\hline Fígado (Liver) & $3,69^{\mathrm{a}}$ & $3,42^{\mathrm{a}}$ & $3,62^{\mathrm{a}}$ & $3,60^{\mathrm{a}}$ & $3,62^{\mathrm{a}}$ & 7,9 \\
\hline Rins (Kidneys) & $0,63^{\mathrm{a}}$ & $0,63^{\mathrm{a}}$ & $0,58^{\mathrm{a}}$ & $0,55^{\mathrm{a}}$ & $0,63^{\mathrm{a}}$ & 9,5 \\
\hline Estômago ${ }^{1}$ (Stomach) & $1,02^{\mathrm{a}}$ & $0,94^{\mathrm{b}}$ & $0,91^{\mathrm{b}}$ & $0,88^{\mathrm{b}}$ & $1,00^{\mathrm{b}}$ & 8,1 \\
\hline Intestino (Intestine) & $5,20^{\mathrm{a}}$ & $4,97^{\mathrm{a}}$ & $5,04^{\mathrm{a}}$ & $4,60^{\mathrm{a}}$ & $4,78^{a}$ & 8,5 \\
\hline
\end{tabular}

${ }_{1}^{1}(\mathrm{P}<0,01)^{2}(\mathrm{P}<0,05)$ Médias seguidas de letras distintas na linha diferem entre si, em contrastes múltiplos.

${ }^{1}(P<0.01)^{2}(P<0.05)$ Means followed by different letters in a line are different by multiple contrasts. 
que não observaram influência da redução do nível de PB da ração de 16 até $12 \%$ sobre a TDP de suínos em crescimento.

Os resultados de pesos absoluto e relativo dos diferentes órgãos avaliados (fígado, rins, estômago e intestino) são apresentados na Tabela 3.

Os tratamentos utilizados influenciaram os pesos absolutos de estômago $(\mathrm{P}<0,05)$ e intestino $(\mathrm{P}<0,05)$ e os pesos relativos de estômago $(\mathrm{P}<0,01)$.

De maneira geral, os maiores valores, tanto de peso absoluto quanto de peso relativo, de estômago e peso absoluto de intestino, foram observados nos animais que receberam a ração com maior nível de proteína bruta.

Keer et al. (1995), trabalhando com leitoas em fase inicial de crescimento até a fase de terminação, verificaram que os animais que receberam a ração com maior nível de PB na ração (19 e 16\%, respectivamente) apresentaram maior peso de órgãos, quando comparados aos que receberam ração com menor nível de PB (14 e 12\%).

Os maiores valores de pesos absoluto e relativo de estômago observados nos animais alimentados com ração contendo maior nível de $\mathrm{PB}$ não são biologicamente explicados, uma vez que o consumo de ração não foi influenciado.

\section{Conclusões}

O nível de $\mathrm{PB}$ da ração para suínos machos castrados dos 15 aos $30 \mathrm{~kg}$ mantidos em ambiente termoneutro pode ser reduzido de 18 para $14 \%$, sem influenciar negativamente o desempenho, desde que as rações sejam devidamente suplementadas com aminoácidos essenciais limitantes.

\section{Literatura Citada}

CANH, T.T.; AARNINK, A.J.A.; SCHUTTE, J.B. et al. Dietary protein affects nitrogen excretion and ammonia emission from slurry of growing-finishing pigs. Livestock Production Science, v.56, p.181-191, 1998.

CHUNG, T.K.; BAKER, D.H. Ideal amino acid pattern for 10kilogram pigs. Journal of Animal Science, v.70, p.31023111, 1992.

DE LA LLATA, M.; DRITZ, S.S.; TOKACH, M.D. et al. Effects of increasing L-lysine $\mathrm{HCl}$ in corn-soybean meal diets on growth performance and carcass characteristics of growingfinishing gilts. Swine Day, p.87-90, 2000.

DONZELE, J.L.; COSTA, P.M.A.; ROSTAGNO, H.S. et al. Efeitos de níveis de energia digestíveis na composição da carcaça de suínos de cinco a quinze quilos. Revista da
Sociedade Brasileira de Zootecnia, v.21, p.1100-1106, 1992.

ESMAY, M.L. Principles of animal environment. Westport CT: ABI Publishing, 1982. 325p.

FIGUEROA, J.L.; LEWIS, A.J.; MILLER, P.S. Nitrogen balance and growth trials with pigs fed low-crude protein, amino acidsupplemented diets. Nebraska Swine Report, p.26-28, 2000.

FIGUEROA, J.L.; LEWIS, A.J.; MILLER, P.S. et al. Valine, isoleucine, and histidine supplementation of low protein, amino acid-supplemented diets for growing pigs. Nebraska Swine Report, p.23-26, 2001.

HANSEN, J.A.; KNABE, D.A.; BURGOON, K.G. Amino acid suplementation of low protein sorghum-soybean meal diets for 20 to 50 kilogram swine. Journal of Animal Science, v.71, p.442-451, 1993.

KEER, B.J.; MCKEITH, F.K.; EASTER, R.A. Effect on performance and carcass characteristics of nursery to finisher pigs fed reduced crude protein, amino acid-supplemented diets. Journal of Animal Science, v.73, p.433-440, 1995.

KIDD, M.T. Dietas de baixa proteína suplementadas com aminoácidos para frangos de corte. In: WORKSHOP LATINO-AMERICANO AJINOMOTO BIOLATINA, 2001, Foz do Iguaçu. Anais ... Foz do Iguaçu: [s.n.], 2001. p.62-67.

LE DIVIDICH, J.L. Effect of environmental temperature on the performance of intensively reared growing pigs. Selezione Veterinaria, v.32, p.191-207, 1991. (Suppl.1)

LOPEZ, J.; GOODBAND, R.D.; ALLEE, G.L. et al. The effects of diets formulated on na ideal protein basis on growth performance, carcass characteristics and thermal balance of finishig gilts housed in a hot, diurnal environment. Journal of Animal Science, v.72, p.367-379, 1994.

MILLER, P.S.; LEWIS, A.J.; WOLVERTON, C.K. et al. Performance of growing-finishing pigs consuming diets formulated on an ideal protein (first four limiting amino acids) basis. Nebraska Swine Report, p.27-30, 1996.

MIYADA, V.S. Novas tendências para a nutrição de suínos em clima quente. In: SILVA, I.J.O. (Ed.) SIMPÓSIO BRASILEIRO DE AMBIÊNCIA E QUALIDADE NA PRODUÇÃO INDUSTRIAL DE SUÍNOS, 1999, Piracicaba. Anais ... Piracicaba: Fundação de Estudos Agrários "Luiz de Queiroz", 1999. p.34-60.

MYER, R.O.; BUCKLIN, R. Influence of a hot and humid rearing environment and plane of nutrition on performance and carcass lean content of growing-finishing swine. Journal of Animal Science, v.73 (Suppl, 1), p.290 (abstr.), 1995.

NATIONAL RESEARCH COUNCIL - NRC. Nutrient requeriments of swine. 10.ed. Washington, D.C.: 1998. $189 \mathrm{p}$.

OLIVEIRA, R.F.M. Efeito do nível de energia digestível e da temperatura ambiente sobre o desempenho e sobre parâmetros fisiológicos e hormonal de suínos dos $\mathbf{1 5}$ aos 30 kg. Viçosa, MG: Universidade Federal de Viçosa, 1996. 139 p. Tese (Doutorado em Zootecnia) - Universidade Federal de Viçosa, 1996.

PARSONS, C.M.; BAKER, D.H. The concept and use of ideal protins in the feeding of nonruminants. In: SIMPÓSIO INTERNACIONAL DE NÃO RUMINANTES, 1994, Maringá. Anais... Maringá: SBZ, 1994. p.119-128.

PATIENCE, J.F. A review of the role of acid-base balance in amino acid nutrition. Journal of Animal Science, v.68, p.398-408, 1990.

PERDOMO, C.C. Considerações sobre o condicionamento 
ambiental na produção de suínos. In: BIAGI, J.D.; CYRINO, J.E.P.; MENTEN, J.F.M. et al. (Eds.). SIMPÓSIO SOBRE NUTRIÇÃO ANIMAL E TECNOLOGIA DA PRODUÇÃO DE RAÇÕES, 1998, Campinas. Anais ... Campinas: Colégio Brasileiro de Nutrição Animal, 1998. p.147-154.

PFEIFFER, A.; HENKEL, H.; VERSTEGEN, M.W.A. et al. The influence of protein intake on water balance, flow rate and apparent digestibility of nutrients at the distal ileum in growing pigs. Livestock Production Science, v.44, p.179-187, 1995.

RHODIMET nutrition guide. 2.ed. France: Rhône-Poulenc Animal Nutrition, 1993. 55p.

ROSTAGNO, H.S.; SILVA, D.J.; COSTA, P.M.A. et al. Composição de alimentos e exigências nutricionais de aves e suínos: Tabelas Brasileiras. Viçosa, MG: Universidade Federal de Viçosa, 1992. 59p.

STATISTICAL ANALYSES SYSTEM - SAS. SAS System for Windows, release 6.12. Cary: 1996. CD-ROM.

SILVA, D.J. Análise de alimentos: métodos químicos biológicos. Viçosa, MG: Universidade Federal de Viçosa, 1990. $166 \mathrm{p}$.

SILVA, I.J.O. Sistemas naturais e artificiais do controle do ambiente - climatização. In: SIMPÓSIO DE AMBIÊNCIA E QUALIDADE NA PRODUÇÃO INDUSTRIAL DE SUÍNOS, 1999, Piracicaba. Anais... Piracicaba: Fundação de Estudos Agrários "Luiz de Queiroz", 1999. p.81-111.
SMITH, J.W.; II O'QUINN, P.R.; TOKACH, M.D. et al. Effects of low-protein, amino acid fortified diets, formulated on a net energy basis, on th growth performance and carcass characteristics of finishing pigs. Swine Day, p.85-89, 1997.

TAVARES, S.L.S.; DONZELE, J.L.; OLIVEIRA, R.F.M. et al. Influência da temperatura ambiente sobre o desempenho e parâmetros fisiológicos de suínos machos castrados dos 30 aos $60 \mathrm{~kg}$. Revista Brasileira de Zootecnia, v.29, p.199-205, 2000.

TUITOEK, K.; YOUNG, L.G.; LANGE, C.F.M. et al. Body composition and protein and fat accretion in various body components in growing gilts feed diets with different protein levels but estimatedto contain similar levels of ideal protein. Journal of Animal Science, v.75, p.1584-1590, 1997.

Recebido em:15/05/02

Aceito em: 06/02/03 